\title{
Significance, progress and prospects for research in simplified cultivation technologies for rice in China
}

\author{
M. HUANG, MD. IBRAHIM, B. XIA AND Y. ZOU* \\ College of Agronomy, Hunan Agricultural University, Changsha 410128, China \\ (Revised MS received 1 June 2010; Accepted 7 September 2010; First published online 17 December 2010)
}

\begin{abstract}
SUMMARY
Simplified cultivation technologies for rice have become increasingly attractive in recent years in China because of their social, economical and environmental benefits. To date, several simplified cultivation technologies, such as conventional tillage and seedling throwing (CTST), conventional tillage and direct seeding (CTDS), no-tillage and seedling throwing (NTST), no-tillage and direct seeding (NTDS) and no-tillage and transplanting (NTTP), have been developed in China. Most studies have shown that rice grown under each of these simplified cultivation technologies can produce a grain yield equal to or higher than traditional cultivation (conventional tillage and transplanting). Studies that have described the influences of agronomic practices on yield formation of rice under simplified cultivation have demonstrated that optimizing agronomy practices would increase the efficiencies of simplified cultivation systems. Further research is needed to optimize the management strategies for CTST, CTDS and NTST rice which have developed quickly in recent years, to strengthen basic research for those simplified cultivation technologies that are rarely used at present (such as NTTP and NTDS), to select and breed cultivars suitable for simplified cultivation and to compare the practicability and effectiveness of different simplified cultivation technologies in different rice production regions.
\end{abstract}

\section{INTRODUCTION}

Rice is the staple food for a large proportion of the world's population (Zhang 2007). World rice production must increase by $c$. $1 \%$ annually to meet the growing demand for food resulting from population growth and economic development (Peng et al. 2004). In the last decade, several major national and international programmes that were initiated with the goals of developing super high-yielding rice to break the rice yield ceiling and feeding the growing population have made significant progress (Zhang 2007). However, the rice yield depends not only on the genetic characters of the rice but also on the management practices (Zou et al. 2003). Crop improvement and crop management have played equal roles in increasing the production of major food crops in the past (Peng \& Yang 2003), but now the relative contributions of breeding and crop management to rice yield increase has shifted to 0·3:0·7 (Peng 2008).

* To whom all correspondence should be addressed. Email: ybzou123@126.com
Moreover, additional rice will have to be produced on less land with less water and less labour (Peng \& Yang 2003). There is no doubt that rice cultivation technologies must be developed that will be labour saving, environmentally friendly and will maintain rice yield potential. Along with the popularization of efficient agriculture in recent years in China, simplified cultivation technologies for rice have become increasingly attractive (Wu et al. 2005). In the present paper, an attempt has been made to interpret research significance, review what has been learned about simplified cultivation technologies for rice in China and discuss unresolved issues that should be addressed in future research.

\section{SIGNIFICANCE OF RESEARCH ON SIMPLIFIED CULTIVATION} TECHNOLOGIES FOR RICE IN CHINA

\section{Social benefits}

In China, about $0 \cdot 60$ of the population sustains on rice (Zhu 2000) and rice production is therefore critical to 


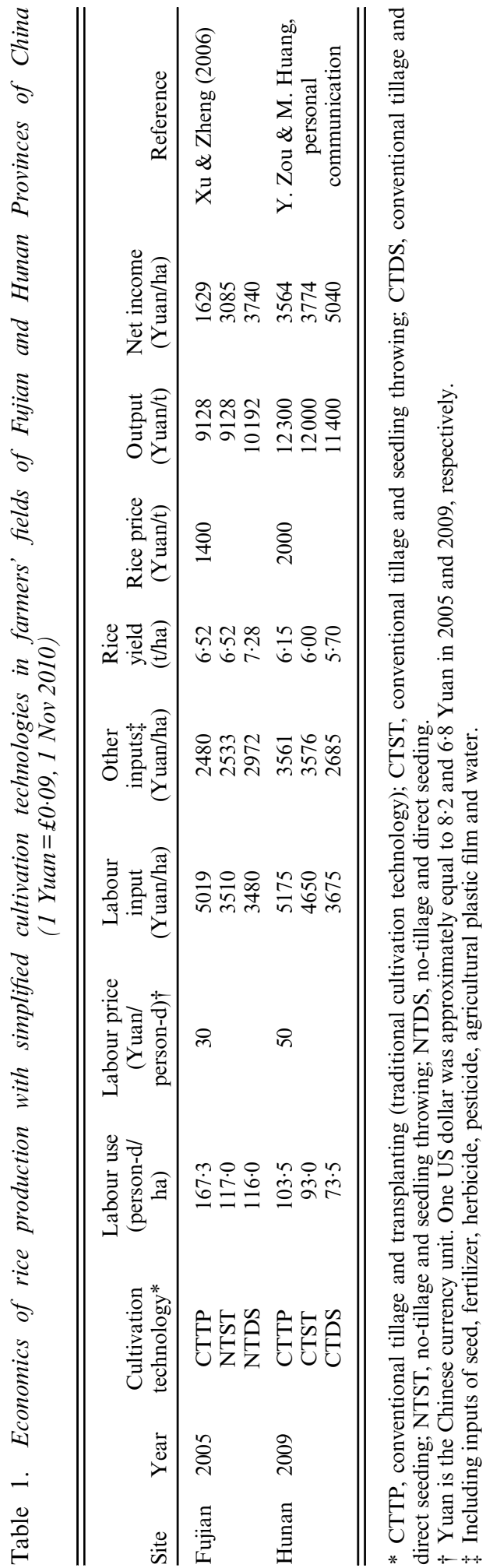

national food security. However, the area of land planted with rice has decreased during the past three decades (Chen et al. 2007a). This is partly attributed to limited labour availability because an increasing number of young farmers have left for jobs in the cities, leaving the older farmers behind (Derpsch \& Friedrich 2009). Therefore, there is an urgent need to develop simplified cultivation technologies to reduce labour requirement.

\section{Economic benefits}

In traditional rice production, conventional tillage and crop establishment methods such as puddled transplanting require a large amount of labour (Bhushan et al. 2007; Chen et al. 2007b), which is becoming increasingly scarce and expensive due to economic development and urbanization in China. Thus, simplifying these tasks can play an important role for improving the economic efficiency of rice production (Table 1).

\section{Environmental benefits}

Soil erosion and scarce water resources are environmental problems that threaten the sustainability of land use in China (Chen et al. 2007a; Zhao et al. 2008). In the mid-20th century, recognition that conventional tillage dramatically accelerated soil erosion led to research and the adoption of no-tillage (Montgomery 2007), which is a simplified land preparation technology. The simplified crop establishment technology of direct seeding offers advantages such as more efficient water use and higher tolerance of water deficit (Balasubramanian \& Hill 2002). Therefore, the development of these simplified cultivation technologies can meet the requirements of protecting the environment.

\section{PROGRESS OF RESEARCH ON SIMPLIFIED CULTIVATION TECHNOLOGIES FOR RICE IN CHINA}

Simplified cultivation technologies for rice are commonly generated by simplifying land preparation, or crop establishment, or both. To date, several simplified cultivation technologies, such as conventional tillage and seedling throwing (CTST), conventional tillage and direct seeding (CTDS), no-tillage and seedling throwing (NTST), no-tillage and direct seeding (NTDS) and no-tillage and transplanting (NTTP), have been developed in China.

\section{NTTP}

NTTP is a simplified cultivation technology that simplifies land preparation. Feng et al. (2006b) reported that NTTP rice produced a higher grain 
Table 2. Grain yield ( tha) of rice with simplified cultivation technologies in experimental fields

\begin{tabular}{|c|c|c|c|c|c|c|c|c|}
\hline \multirow[b]{2}{*}{ Cultivar } & \multirow{2}{*}{$\begin{array}{l}\text { Cropping } \\
\text { season* }\end{array}$} & \multicolumn{6}{|c|}{ Cultivation technology } & \multirow[b]{2}{*}{ Reference } \\
\hline & & СТTP & NTTP & CTST & CTDS & NTST & NTDS & \\
\hline Jinyou 255 & ES & $6 \cdot 38$ & & $6 \cdot 48$ & & $6 \cdot 73$ & & Wu et al. $(2009 a)$ \\
\hline Jinyou 402 & ES & $6 \cdot 03$ & & & $7 \cdot 12$ & & & Liu et al. (2003) \\
\hline Jinyou 974 & ES & $7 \cdot 00$ & & $7 \cdot 47$ & & $7 \cdot 60$ & & Wu et al. $(2009 a)$ \\
\hline Xiangliangyou 68 & ES & $5 \cdot 53$ & & & $6 \cdot 43$ & & & Liu et al. (2003) \\
\hline Yuexiangzhan & ES & $8 \cdot 47$ & & & & $8 \cdot 47$ & & Liu et al. (2002) \\
\hline Zhongzu 1 & ES & $4 \cdot 69$ & & & $5 \cdot 08$ & & & Liu et al. (2003) \\
\hline Jinyou 207 & LS & $7 \cdot 84$ & & 8.03 & & $8 \cdot 20$ & & Wu et al. $(2009 a)$ \\
\hline Qiuyou 1025 & LS & & & & 8.69 & & $8 \cdot 96$ & $\begin{array}{c}\text { Zhou \& Tang } \\
\text { (2008) }\end{array}$ \\
\hline Zhongyou 288 & LS & $6 \cdot 45$ & & $7 \cdot 02$ & & $7 \cdot 13$ & & Wu et al. $(2009 a)$ \\
\hline \multirow[t]{5}{*}{ Liangyoupeijiu } & SS & $8 \cdot 49$ & $8 \cdot 59$ & & $8 \cdot 78$ & & & Feng et al. $(2006 b)$ \\
\hline & SS & $10 \cdot 31$ & $10 \cdot 41$ & & $10 \cdot 53$ & & $10 \cdot 96$ & Cheng et al. $(2008 b)$ \\
\hline & SS & $11 \cdot 25$ & $10 \cdot 26$ & & $9 \cdot 56$ & & & Mo et al. (2008) \\
\hline & SS & $8 \cdot 62$ & & & $9 \cdot 58$ & & & Zhang et al. $(2006 b)$ \\
\hline & SS & & & & $8 \cdot 70$ & & $9 \cdot 27$ & Feng et al. $(2006 a)$ \\
\hline Mian2you 838 & SS & $7 \cdot 17$ & & & $7 \cdot 36$ & & & Zhang et al. $(2006 b)$ \\
\hline Qiannanyou 2058 & SS & 10.99 & $11 \cdot 17$ & & & & & Dong et al. (2008) \\
\hline Shanyou 63 & SS & 8.72 & & $9 \cdot 67$ & & & & Dai et al. (2000) \\
\hline Xiangwanxian 11 & SS & 6.06 & & & $6 \cdot 81$ & & & Zhang et al. $(2006 b)$ \\
\hline Yangdao 6 & SS & 6.98 & & & $7 \cdot 12$ & & & Zhang et al. $(2006 b)$ \\
\hline Yanyou KC57 & SS & $9 \cdot 99$ & & $10 \cdot 23$ & & & & Dai et al. (2000) \\
\hline Zhunliangyou 527 & SS & $11 \cdot 15$ & & & & & $9 \cdot 89$ & Su \& Qian (2009) \\
\hline
\end{tabular}

* ES, early season (from late March to late July); LS, late season (from mid-June to end-October); SS, single season (from April to September).

$\dagger$ CTTP, conventional tillage and transplanting (traditional cultivation technology); NTTP, no-tillage and transplanting; CTST, conventional tillage and seedling throwing; CTDS, conventional tillage and direct seeding; NTST, no-tillage and seedling throwing; NTDS, no-tillage and direct seeding.

yield (Table 2) than that of conventional tillage and transplanting (CTTP) rice, due to enhanced root properties. At maximum tillering, root/shoot ratio, root dry weight, root absorbing surface area, amounts of ${ }^{32} \mathrm{P}$ absorbed by roots and the root oxidizing ability of NTTP rice were higher than those of CTTP rice. At maturity, root weight, root length, root weight density and root length density in the $0-50 \mathrm{~mm}$ soil layer, specific root length in 50-100 and $100-200 \mathrm{~mm}$ soil layer of NTTP rice were higher compared to those of CTTP rice. Similar results were observed by Cheng et al. (2008a) and Cheng et al. (2008b) found that the uptake of nitrogen in NTTP rice was higher than that in CTTP rice. Dong et al. (2008) stated that the higher grain yield seen in NTTP rice than in CTTP rice (Table 2) was related to its higher dry matter accumulation and root oxidizing ability during grainfilling stage and delayed leaf senescence. However, Mo et al. (2008) observed that, in a 5-year fixed field experiment, the grain yield of NTTP rice was equal to or higher than CTTP rice during the first 4 years, but significantly lower (Table 2) in the fifth year.

Moreover, there have been reports describing the effects of nitrogen $(\mathrm{N})$ application rates on NTTP rice
(Feng et al. 2004; Han et al. 2009; Zhao et al. $2009 a, b$ ). These reports indicated that the grain yield of NTTP rice was quadratically related to the N application rate, and that its root absorbing surface area, tillering capability, leaf area index and dry matter accumulation increased with increasing $\mathrm{N}$ application rate, whereas its dry matter translocation percentage from vegetative organs to grains, grain/leaf ratio, harvest index and $\mathrm{N}$ use efficiency such as $\mathrm{N}$ recovery efficiency, $\mathrm{N}$ physiological efficiency, $\mathrm{N}$ agronomic efficiency and $\mathrm{N}$ partial factor productivity all decreased with increasing $\mathrm{N}$ application rate.

\section{CTST}

CTST is a simplified cultivation technology that is generated by partly simplifying the crop establishment task. In the early development of CTST, a frequent question was how do the horizontal rice seedlings stand up after throwing? Li et al. (1998) found that, at the base of the horizontal rice seedling, the elongating cells of the lower side grew faster than those of the upper side, which led to a curvature zone whereby the initially horizontal seedling became erect. However, 
the standing up of CTST rice could be affected by seedling age (Han \& Ma 1995; Li et al. 1998; Dai et al. 2001a), seedling quality (Zhao et al. 1996; Zhang et al. 2000; Dai et al. 2001a), whether or not soil existed on seedling roots at throwing (Zhang et al. 1993; Han \& Ma 1995; Dai et al. 2001a), seedling posture after throwing (Dai et al. 2001a), water depth in paddy field (Han \& Ma 1995; Dai et al. 2001a) and the temperature, humidity and oxygen concentration of growing environment (Li et al. 1998; Dai et al. 2001a). In general, the following were found to benefit standing: younger seedlings, better seedling quality, the presence of soil on seedling roots at throwing, a bigger angle between seedling and ground after throwing (i.e. the seedlings that are more upright after throwing), shallower water in the paddy field and higher temperature, humidity and oxygen concentration of the growing environment. Moreover, Lü et al. (2001) stated that the standing up of CTST rice could be regulated by the application of exogenous calcium $\left(\mathrm{Ca}^{2+}\right)$, because it is a major component of the gravitropic responses of plant organs.

Under high-yielding management conditions, the grain yield of CTST rice was higher than that of CTTP rice (Table 2), owing to its biological superiority and an improved paddy field environment. The CTST rice had several advantages: a larger root system and stronger root activity; the setback caused by uprooting and transplanting was either smaller or non-existent; more tillers, greater green leaf area, more panicles and spikelets per unit land area; and a thicker photosynthetic layer during grain filling (Zhang et al. 1998; Dai et al. 2000). In addition, compared to CTTP rice paddy fields, the temperature, nutrient levels and resistance of soil around tiller nodes were improved in CTST rice field (Dai et al. 2001b). Furthermore, Shi et al. (1997) and Dai et al. (2001c) reported that canopy microclimates, including light, temperature, humidity and ventilation, were also improved in CTST rice paddy fields. However, other factors were inferior in CTST rice, such as a lower proportion of panicle-bearing tillers, higher proportion of small panicles and weaker resistance to root lodging (Dai et al. 2000).

In addition, some studies have demonstrated that the yield formation of CTST rice could be influenced by the presence or absence of soil on seedling roots at throwing (Zhang et al. 1993), throwing density (Chen \& Pan 2000) and $\mathrm{N}$ management strategy (Fu et al. 1999; Chen \& Pan 2000; Tao et al. 2002; Zhang et al. 2006a). Using the Zadoks et al. (1974) decimal code for growth stages (GSs) of cereals, generally, for young (GS13-14) and medium age (GS15-18) seedlings, having soil on their roots at throwing was found to increase the leaf area index, dry matter production, spikelets per panicle, spikelets per unit land area and the grain yield of CTST rice. In the studies of Fu et al. (1999), Chen \& Pan (2000), Tao et al. (2002) and
Zhang et al. (2006a), it was found that increasing the throwing density appropriately and $\mathrm{N}$ application at a later stage could increase the proportion of fertile tillers, root activity, plant nitrogen uptake, photosynthetic rate of flag leaf and dry matter accumulation after heading, as well as the grain yield of CTST rice.

\section{CTDS}

CTDS greatly simplifies crop establishment tasks. Seed germination, however, is hindered by hypoxia and its negative effect on subsequent growth is one of the major constraints that limit grain yield of CTDS rice. Fortunately, many studies have shown that seed coating is a useful technique for overcoming this problem (Ota 1982; Yamauchi \& Chuong 1995; Jeyanny et al. 2007). In recent years, some seed coating agents, such as XSW-3 and WHW-23, have been developed for CTDS rice production in China. The active ingredients of these coatings include insecticide (imidacloprid), fungicide (prochloraz), plant growth regulator (IAA, NAA, DCPTA, etc.) and micronutrient $(\mathrm{Zn}, \mathrm{Cu}, \mathrm{Mo}, \mathrm{Mg}$, etc.). Xiong et al. (2005) reported increases in germination, seedling growth, resistance to stressful environments, diseases and pests, and grain yield in CTDS rice seeds coated with XSW-3. Similar results were observed when rice seeds were coated with WHW-23 (Li et al. 2006).

In addition, high-weed infestation is another major constraint to widespread adoption of CTDS in rice production (Phuong et al. 2005). Leptochloa chinensis, Echinochloa crusgalli and Juncellus serotinus are the dominant weeds in CTDS fields. Significant negative linear relationships between densities of $L$. chinensis, E. crusgalli and J. serotinus and panicles per unit land area, spikelets per panicle, grain weight and grain yield of rice in CTDS fields were found by Zhang et al. (1996), Guan et al. (2001) and Dong et al. (2003), who also calculated the economic threshold weed density for spraying to control the weeds economically and effectively. It was suggested that $L$. chinensis could be controlled by spraying pretilachlor $30 \%$ EC diluted $2.5 \mathrm{ml} / 1$ and applied at 600 litre/ha and cyhalofop-butyl $10 \%$ EC diluted $2.0 \mathrm{ml} / 1$ and applied at 600 litre/ha when its densities reached 0.73 and 1.51 plants $/ \mathrm{m}^{2}$, respectively. E. crusgalli and J. serotinus could be controlled by spraying a combination of quinclorac $50 \%$ WP diluted $1.0 \mathrm{~g} / 1$ and pyrazosulfuron-ethyl $10 \% \mathrm{WP}$ diluted $0.5 \mathrm{~g} / \mathrm{litre}$, both at 450 litre/ha, when densities reached 1 and 30 plants $/ \mathrm{m}^{2}$, respectively.

Under normal conditions, most reports stated that the grain yield of CTDS was higher compared to that of CTTP (Liu et al. 2003; Feng et al. 2006b; Zhang et al. 2006b; Cheng et al. 2008b); however, Mo et al. (2008) observed that the grain yield of CTDS was lower than that of CTTP (Table 2). However, for yield 
components, all these studies indicated that CTDS rice was characterized by higher panicles per unit land area, but lower spikelets per panicle. Moreover, Yu et al. (2008) found that the main tillering zone of CTDS rice was located between the phytomers in ranks 3-5. Wang et al. (2002) reported that dry matter accumulation before and after heading were related quadratically and linearly, respectively, to grain yield in CTDS rice.

Many studies have been carried out to seek suitable cultivars or agronomic practices to improve grain yield of CTDS rice. For suitable cultivars, Qian et al. (2008) stated that, under CTDS condition, the leaf area index, dry matter accumulation, the proportion of dry matter translocated from vegetative organs to grains and panicle number per unit land area of medium panicle-type cultivars were higher than those of small and large panicle-type cultivars, which further resulted in a higher grain yield in the middle panicle-type cultivars. For suitable agronomic practices, Xue et al. (2008) reported that grain yield of CTDS rice was parabolically related to seeding date, and panicles per unit land area, spikelets per panicle, grain-filling rate and individual grain weight were associated with sunshine duration during tillering, sunshine duration during panicle initiation to pollen meiosis, minimum temperature during flowering and average minimum temperature or sunshine duration during the 20 days before and after heading, respectively. Lu et al. (1999) stated that population quality, photosynthetic area at a later stage, dry matter accumulation and grain yield of CTDS rice could be improved by properly reducing seeding density. $\mathrm{Xu}$ et al. (2009) reported that compared to farmers' fertilizer practice, tiller number and the leaf area index and dry matter accumulation at early GS were decreased, whereas the proportion of fertile tillers, root activity during grain filling, photosynthetic rate and ATPase activity in flag leaves and grain yield were increased in CTDS rice under site-specific nitrogen management. Shen et al. (2005) found that plastic film mulching increased soil temperature and $\mathrm{N}$ use efficiency but reduced weeds and water consumption in CTDS rice paddy fields, and grain yield of CTDS rice was improved due to increased panicle number per unit land area because the high temperature accelerated early tillering. He et al. (2005) stated that the proportion of fertile tillers, dry matter accumulation, chlorophyll content in canopy leaves, panicles per unit land area, panicle length, spikelets per panicle, filled spikelets per panicle, individual grain weight and grain yield under furrow irrigation were higher than those under continuously flooded system in CTDS rice. Furthermore, these positive effects of furrow irrigation on CTDS rice could be influenced by border width (He et al. 2003, 2004). In general, the positive effects were increased with narrower border width.
NTST

NTST greatly simplifies land preparation and partly simplifies crop establishment. Jiang et al. (2005) reported that NTST rice seedlings took longer to stand during early stages but less time during late stages than those of CTST rice, and its total standing time was the same as that of CTST rice. In contrast, $\mathrm{Wu}$ et al. (2009b) observed that the total seedling standing time of NTST rice was 2-3 days less than that of CTST rice, and stated that shallower water depth in paddy field, using younger seedlings, appropriately increasing $\mathrm{N}$ application at the early growth, incorporating straw appropriately, dry-raising seedlings on plastic trays, spraying paclobutrazol at GS12 (Zadok et al. 1974) and soaking seed by $\alpha$-naphthylacetic acid were beneficial to the seedling standing of NTST rice. However, Jiang et al. (2005) reported that the root number of NTST was higher than that of CTST rice, but its root growth was blocked at a shorter length during the seedling standing period. Consistently, Wu et al. (2009c) stated that root dry weight of NTST rice was lower than that of CTTP rice, and most of its roots were distributed in the top $50 \mathrm{~mm}$ soil layer. However, Wu et al. (2008b) observed that uptake of $\mathrm{N}$, phosphorus (P) and potassium $(\mathrm{K})$ followed the order that NTST rice $>$ CTST rice $>$ CTTP rice in both early and late rice-growing seasons, and there was a tight positive relationship between uptake of $\mathrm{N}, \mathrm{P}$ and $\mathrm{K}$ to grain yield. Furthermore, Liu et al. (2002) reported that the photosynthetic rate in flag leaves of NTST rice was higher than that of CTST rice, while its flag leaf senescence was delayed compared to that of CTST rice. Similar results were observed by $\mathrm{Xu} \&$ Jiang (2007) and Wu et al. (2009a), who further indicated that the physiological superiority during grain-filling stage always led to a higher grain-filling percentage or larger panicle size in NTST rice, and resulted in a higher or equal grain yield compared to that produced in CTST rice (Table 2).

In addition, some studies have been conducted on the effects of agronomic practices on yield formation of NTST rice. Tian et al. (2009) reported that the grain yield of NTST rice was increased with decreasing seedling age at throwing. Qin et al. (2006) stated that increasing $\mathrm{N}$ application would decrease grain-filling but increase root activity, dry matter accumulation, dry matter translocation percentage from vegetative organs to grains, grain/ leaf ratio, panicles per unit land area, plant height and grain yield in NTST rice. However, Wu et al. (2008a) reported that $\mathrm{N}$ physiological efficiency, $\mathrm{N}$ agronomic efficiency and harvest index of NTST rice decreased with increasing $\mathrm{N}$ application, and further found that increasing $\mathrm{K}$ application appropriately could increase N recovery efficiency in NTST rice. 


\section{NTDS}

NTDS greatly simplifies both land preparation and crop establishment. Cheng et al. (2008a) observed that root/shoot ratio, root dry weight, root length and root-oxidizing ability of NTDS rice were higher than those of CTDS rice. Furthermore, Feng et al. (2006b) found that the amount of ${ }^{32} \mathrm{P}$ absorbed by roots at maximum tillering, booting and full heading, and ${ }^{32} \mathrm{P}$ translocation from roots to aboveground parts at booting of NTDS rice were higher compared to those of CTDS rice. Consistently, Cheng et al. (2008b) stated that, compared with CTDS rice, uptake of $\mathrm{P}$ and $\mathrm{K}$ was higher in NTDS rice. However, Feng et al. (2006a) reported that the net photosynthetic rate at later GS and spikelets per panicle of NTDS rice were higher than that of CTDS rice, while Zhou \& Tang (2008) observed that both spikelets per panicle and grain-filling were higher in NTDS rice than in CTDS rice. In addition, Feng et al. (2006a) and Zhou \& Tang (2008) also showed that the grain yield of NTDS was higher than that of CTDS (Table 2). However, Su \& Qian (2009) reported that the grain yield of NTDS rice was lower (Table 2) than that of CTTP rice owing to its shorter growth period and lower proportion of fertile tillers.

Moreover, there were differences observed in grain yield between inbred and hybrid rice under NTDS conditions (Yang et al. 2007; Jiang et al. 2008). Both studies showed that under NTDS condition grain yield of hybrid rice was higher that that of inbred rice, and Jiang et al. (2008) stated that stronger tillering ability, more spikelets per panicle and higher grain weight of hybrid rice were responsible for its higher grain yield. On the other hand, grain yield of NTDS rice could be affected by management practices. Lei et al. (2007) reported that the grain yield of NTDS rice was improved by using calcium oxide-coated seeds, which allowed a high emergence rate. Ying et al. (2008) and Zhou et al. (2008) confirmed that the optimum time of seeding for late-season NTDS rice was early June. Lei et al. (2009) observed that heading and maturity of NTDS rice were delayed with increasing basal fertilizer, and its grain yield was parabolically related with the basal fertilizer dose.

\section{PROSPECTS OF RESEARCH ON SIMPLIFIED CULTIVATION TECHNOLOGIES FOR RICE IN CHINA}

\section{Optimizing management strategies and strengthening basic research}

Of the above-mentioned simplified cultivation technologies, CTST, CTDS and NTST have been gradually adopted by more and more farmers in China. However, the farmers basically follow the traditional agronomic practices for field management. A number of previous studies have confirmed that some of these traditional management practices, such as $\mathrm{N}$ application, utilize resources ineffectively and have negative impacts on the environment (Peng et al. 2006; Guo et al. 2010). Thus, great attention should be paid to optimize the management strategies for CTST, CTDS and NTST rice to obtain environmental and economic benefits. On the other hand, NTTP and NTDS are still rarely used in rice production in China. Initially, it is important to determine the yield performance and stability of NTTP and NTDS rice and systematically identify their yield formation mechanisms.

\section{Selecting and breeding suitable cultivars}

As reviewed above, the growth and physiological characteristics of rice plants grown under simplified cultivation are different from those under traditional cultivation. Moreover, significant rice genotype $\times$ cultivation method interactions have been reported in tests involving diverse genotypes (Hayashi et al. 2007; Joshi et al. 2007). Therefore, rice breeders must tailor cultivars to simplified cultivation. The super rice project, initiated in 1996 in China (Yuan 1997) with the goal of developing super high-yielding rice, has made great advancements (Cheng \& Min 2001). From 2005 to 2007, 61 cultivars were approved as super high-yielding rice by the National Ministry of Agriculture (Huang \& Zou 2009). These cultivars can produce $15-20 \%$ more yield than the traditional hybrid rice under traditional cultivation (Wang et al. 2005), but it is still not clear whether their yield potential is maintained under simplified cultivation. Hence, there is a need to investigate the growth, physiology and yield responses of these genotypes to simplified cultivation. This may present an opportunity to select super high-yielding cultivars for simplified cultivation.

\section{Evaluating practicability and effectiveness}

In China, rice-based cropping systems are diverse due to the existence of various agro-climatic zones (Xing et al. 2002). Moreover, social-economic conditions are also different in different regions. This raises a question: which simplified cultivation technology is the most appropriate in different rice-based cropping systems and socio-economic conditions? Currently, limited information is available on this issue. Therefore, future research is needed on evaluating practicability and effectiveness of above-mentioned simplified cultivation technologies in different rice production regions.

We thank the International Rice Research Institute, the German Federal Ministry of Economic Cooperation and Development, the Ministry of Agriculture of China and the China National Rice Research Institute for financial support. 


\section{REFERENCES}

Balasubramanian, V. \& Hill, J. E. (2002). Direct seeding of rice in Asia: emerging issues and strategic research needs for the 21st century. In Direct Seeding: Research Strategies and Opportunities (Eds S. Pandey, M. Mortimer, L. Wade, T. P. Tuong, K. Lopez \& B. Hardy), pp. 15-39. Los Baños, Philippines: International Rice Research Institute.

Bhushan, L., Ladha, J. K., Gupta, R. K., Singh, S., TirolPadre, A., Saharawat, Y. S., Gathala, M. \& Pathak, H. (2007). Saving of water and labor in a rice-wheat system with no-tillage and direct seeding technologies. Agronomy Journal 99, 1288-1296.

Chen, L. Y., XiaO, Y. H., TANG, W. B. \& LeI, D. Y. (2007a). Practices and prospects of super hybrid rice breeding. Rice Science 14, 71-77.

Chen, S., Xia, G. M., Zhao, W. M., Wu, F. B. \& Zhang, G. P. (2007b). Characterization of leaf photosynthetic properties for no-tillage rice. Rice Science 14, $283-288$

Chen, X. R. \& Pan, X.H. (2000). Effects of different nitrogen application methods and different densities on the yield of rice associated with scattered-planting with long-age seedlings. Acta Agriculturae Universitis Jiangxiensis 22, 322-326 (in Chinese).

Cheng, S. H. \& Min, S. K. (2001). Super rice breeding in China. Chinese Rice Research Newsletter 9, 13-15.

Cheng, Z. W., Zou, Y. B., Liu, W., Mo, Y. L., Jiang, P. \& ZHAN, K. (2008a). Effects of no-tillage on root characteristics of super hybrid rice Liangyoupeijiu. Crop Research 22, 239-242 (in Chinese).

Cheng, Z. W., Zou, Y. B., Liu, W., Mo, Y. L., JiAng, P. \& ZHAN, K. (2008b). Effects of different tillage and cultivation methods on yield formation and nutrient uptake of super hybrid rice. Crop Research 22, 259-262 (in Chinese).

Dai, Q. G., Zhang, H. C., Huo, Z. Y., Xu, K. \& Qiu, F. (2000). Characteristics of growth and yield formation of broadcasting-seedling of rice. Jiangsu Agricultural Research 21, 1-7 (in Chinese).

Dai, Q. G., Zhang, H. C., Su, B. L., Qiu, F., Huo, Z. Y. \& $\mathrm{XU}, \mathrm{K}$. (2001a). The eco-physiological mechanism of growth, development and yield formation of broadcasted rice seedlings I. Standing and establishment of rice seedlings and its eco-physiological characteristics. Acta Agronomica Sinica 27, 278-285 (in Chinese).

Dai, Q. G., Huo, Z. Y., Zhang, H. C., Su, B. L., Xu, K. \& QIU, F. (2001b). The eco-physiological mechanism of growth, development and yield formation of broadcasted rice seedlings II. The characteristics of spatial distribution of plant on perpendicular and its eco-physiological effect. Acta Agronomica Sinica 27, 600-611 (in Chinese).

DaI, Q. G., Xu, K., Zhang, H. C., Su, B. L., Huo, Z. Y. \& QIU, F. (2001c). Eco-physiological mechanism of growth, development and yield formation of broadcasted rice seedlings III. The characteristics of the spatial distribution of plant on level and its eco-physiological effects. Acta Agronomica Sinica 27, 802-810 (in Chinese).

Derpsch, R. \& Friedrich, T. (2009). Development and current status of no-till adoption in the world. In Proceedings of the 18th Triennial Conference of the International Soil Tillage Research Organization (ISTRO), Izmir, Turkey. (On CD-ROM). Article T1-041, pp. 1-16. The Netherlands: ISTRO.
Dong, A. L., Feng, Y.H., Zhao, T.J., Han, G. G., PANG, X. S., Song, B. \& FAN, W. G. (2008). Effects of no-tillage on growth properties and yield in transplanted hybrid rice. Journal of Mountain Agriculture and Biology 27, 471-475 (in Chinese).

Dong, L. Y., Shen, J. L., Gao, T. C., Zhou, B. J. \& ZhANG, Y. (2003). The eco-economic threshold and the critical period for controlling Leptochloa chinensis in direct-sowing rice fields. Journal of Nanjing Agricultural University 26, 41-45 (in Chinese).

Feng, Y. H., Zou, Y. B., Ao, H. J. \& Wang, S. H. (2004). Impact of different fertilizer-N application on growth and yield formation of transplanted rice under zero tillage and conventional tillage conditions. Crop Research 3, 145-150 (in Chinese).

Feng, Y. H., Zou, Y. B., Buresh, R. J., Xu, G. L., Ao, H. J. \& WANG, S. H. (2006a). Effects of no-tillage and direct broadcasting on soil physical and chemical properties and growth and yield formation in hybrid rice. Acta Agronomica Sinica 32, 1728-1736 (in Chinese).

Feng, Y. H., Zou, Y. B., Buresh, R. J., Li, H. S., GaO, Y. \& Xu, G. L. (2006b). Effects of different tillage system on root properties and the yield in hybrid rice. Scientia Agricultura Sinica 39, 693-701 (in Chinese).

Fu, Y. K., WANG, L. C., Zhang, F. Y., LiU, D. S., DenG, Y. B., Zhu, H.S., Jin, L. \& LiU, Q. J. (1999). Effect of decreasing nitrogen rates on yield of rice transplanted by throwing-seedlings. Journal of Shengyang Agricultural University 30, 112-114 (in Chinese).

Guan, L., Chen, J., Chen, G., Cheng, M., Shen, Q. \& ZhANG, S. (2001). Study on infestation, damage and complex control targets of Echinochloa crusgalli and Juncellus serotinus in wet-land direct-sowing rice fields. Acta Agriculturae Shanghai 17, 79-81 (in Chinese).

Guo, J. H., Liu, X. J., Zhang, Y., Shen, J. L., Han, W. X., Zhang, W. F., Christie, P., Goulding, K. W. T., Vitousek, P. M. \& Zhang, F.S. (2010). Significant acidification in major Chinese croplands. Science 327, $1008-1010$.

HAN, F. C. \& MA, N. Y. (1995). Factors affecting and measures to improve seedling-standing in seedlingthrowing culture of hybrid rice. Hybrid Rice 10(6), 24-26 (in Chinese).

Han, G. G., Feng, Y.H., ZhaO, T. J., Dong, A. I., PAN, X. S., Song, B. \& FAN, W. G. (2009). Effects of fertilizer- $\mathrm{N}$ application rate and tillage patterns on root properties and yield of transplanted hybrid rice Qiannanyou 2058. Research of Agricultural Modernization 30, 225-228 (in Chinese).

Hayashi, S., Kamoshita, A., Yamagishi, J., Kotchasatit, A. \& Jongdee, B. (2007). Genotypic differences in grain yield of transplanted and direct-seeded rainfed lowland rice (Oryza sativa L.) in northeastern Thailand. Field Crops Research 102, 9-21.

He, C. L., Chen, B., Gou, R. F. \& Huang, C. Z. (2005). Effects of water penetration in furrow irrigation on the dry matter accumulation and yield of directly sown rice. Agricultural Research in the Arid Areas 23, 65-69 (in Chinese).

He, C. L., Gou, R. F. \& Chen, B. (2003). Influence of irrigation and penetration through ditch on shape and 
function of direct-seedling rice root system. Research of Agricultural Modernization 24, 452-455 (in Chinese).

He, C. L., Gou, R. F. \& Chen, B. (2004). Influence on the growth characteristics of the roots and leaves of directseeding rice by penetration through ditch irrigation. Journal of Irrigation and Drainage 23, 52-55 (in Chinese).

Huang, M. \& Zou, Y. B. (2009). Comparison of grain filling characteristics between two super rice cultivars with remarkable difference in grain weight. World Applied Sciences Journal 6, 674-679.

Jeyanny, V., Syed Omar, S. R., Juraimi, A. S. \& Azmi, M. (2007). Effects of rice seeds coated with calcium peroxide on rice seedlings establishment. World Journal of Agricultural Sciences 3, 17-22.

Jiang, L. G., Li, R. P., Wei, S. Q., Zhang, P. G., Xu, S. H., Lang, N., Dong, D. F., Chen, N.P., Lu, F. Y. \& QIN, H. D. (2005). Root growth and standing characteristics of Jinyou 253 seedlings under no-tillage with cast transplantation. Journal of Guangxi Agricultural and Biological Science 24, 30-34 (in Chinese).

Jiang, Z. P., Huang, S. M., Wei, G. P., Chen, B. L., Meng, Y. C., Su, T. M. \& Li, Z. J. (2008). Effects of no-tillage direct seeding on the soil properties and the yield formation of conventional rice and hybridize rice. Guangdong Agricultural Sciences (2), 3-5, 12 (in Chinese).

Joshi, A. K., Chand, R., Arun, B., Singh, R. P. \& Ortiz, R. (2007). Breeding crops for reduced-tillage management in the intensive, rice-wheat systems of South Asia. Euphytica 153, 135-151.

Lei, C. Y., XING, D. Y., Luo, Y. M., YAnG, W. M., HuAng, H. L. \& FAN, D. P. (2007). Preliminary research on the effects of direct sowing with zero-tillage by different rice seed coatings. Journal of Anhui Agricultural Sciences 35, 6070-6071 (in Chinese).

Lei, C. Y., Yang, W. M., Gao, J. H., Xu, S. H., Liu, J.P., Zhou, Y. F. \& XING, D. Y. (2009). Optimum application rates of basal fertilizer of late-season rice with zero-tillage and direct sowing. Hubei Agricultural Sciences 48, 809810 (in Chinese).

Li, J. J., Xiong, Y. F., Xiong, H. R., Zou, Y. B., Wen, Z. Y. \& LiU, W. (2006). Effects of seed pelleting agent WHW-23 on seedling growth and enzyme activities of direct-seeded rice. Journal of Hunan Agricultural University (Natural Sciences) 32, 120-123 (in Chinese).

Li, K. W., Wang, Z., Gu, Y.J., XIONG, F. \& Wu, Z. G. (1998). The effects of inner-outer factors on bending-up of scattering-rice. Journal of Jiangsu Agricultural College 19, 53-58 (in Chinese).

Liu, J., Huang, Q., Fu, H., Lu, X. M., Liu, H. Z. \& Li, K. H. (2002). Physiological mechanism of high and stable yield of no-tillage cast-transplanted rice. Agricultural Sciences in China 1, 404-409.

Liu, S. Q., Yang, A. Q., He, D. F., Song, Y. H. \& Zhou, W. M. (2003). Growth characteristics of directseed culture of early rice and its high-yielding cultural techniques. Hybrid Rice 18, 43-44 (in Chinese).

Lu, Z. R., Wang, G. Z., TANG, J. P. \& Zhu, P. M. (1999). Effects of density on grain yield and population quality in direct sowing rice. Acta Agriculturae Shanghai 15, 61-64 (in Chinese).

Lü, B., Zhu, H. W., Liang, J.S., Cao, X. Z. \& Song, P. (2001). Effects of exogenous calcium and its related substances on scattering-planted rice seedlings' bending upward. Acta Agronomica Sinica 27, 55-58 (in Chinese).
Mo, Y. L., Jiang, P., Zhan, K., Huang, M. \& Zou, Y. B. (2008). Effects of different tillage methods on physiological characters of flag leaf and grain filling in super hybrid rice. Crop Research 22, 235-242 (in Chinese).

Montgomery, D. R. (2007). Soil erosion and agricultural sustainability. Proceedings of the National Academy of Sciences USA 104, 13268-13272.

Ота, Y. (1982). Promotion of emergence and establishment of rice seedlings by using calcium peroxide-coated seeds in direct sowing on flooded paddy field. Japanese Agricultural Research Quarterly 15, 221-226.

Peng, S. (2008). The importance of improved crop management to world rice production. Crop Research 22, 207-208 (in Chinese).

Peng, S., Buresh, R. J., Huang, J., Yang, J., Zou, Y., Zhong, X., Wang, G. \& Zhang, F. (2006). Strategies for overcoming low agronomic nitrogen use efficiency in irrigated rice systems in China. Field Crops Research 96, $37-47$.

Peng, S., Huang, J., Sheehy, J. E., Laza, R. C., Visperas, R. M., Zhong, X., Centeno, G.S., Khush, G. S. \& Cassman, K. G. (2004). Rice yields decline with higher night temperature from global warming. Proceeding of the National Academy of Sciences USA 101, 9971-9975.

Peng, S. \& YAng, J. (2003). Current status of the research on high-yielding and high efficiency in resource use and improving grain quality in rice. Chinese Journal of Rice Science 17, 275-280.

Phuong, L. T., Denich, M., Vlek, P. L. G. \& Balasubramanian, V. (2005). Suppressing weeds in direct-seeded lowland rice: effects of methods and rates of seeding. Journal of Agronomy and Crop Science 191, 185-194.

Qian, Y.F., Zhang, H. C., Li, J., Chen, Y., Guo, Z. H., Wu, W. G., DAI, Q. G., Huo, Z. Y., Xu, K., LI, D. J. \& ZHou, Y. Y. (2008). Studies on yield and characteristics of plant population quality of direct-seeded rice cultivars of different panicle types. Acta Agriculturae Universitis Jiangxiensis 30, 766-772 (in Chinese).

Qin, H. D., TAN, S. N., Zeng, H. Z., JiAnG, L. G., He, L. J., Li, R. P., YANG, W. F., Lu, F. Y. \& TANG, M. Y. (2006). Effects of tillage patterns and nitrogen application levels on population quality and yield of cast transplanting rice. Journal of Guangxi Agricultural and Biological Science 25, 315-320 (in Chinese).

Shen, K. R., Li, J. J., Wang, X. C., Shen, X., LiU, J., Xu, X. H., Guan, Y.F., CaO, J. \& Wei, G. J. (2005). Demonstration effects and mechanism of paddy-rice wet cultivation with plastic-film mulching. Hubei Agricultural Sciences 5, 28-32 (in Chinese).

Shi, H. Y., Piao, Y., Zhang, J., Sui, D. \& Zheng, Y. F. (1997). Studies on factors of microclimate in field of rice transplanted by throwing-seedlings. Journal of Shengyang Agricultural University 28, 268-273 (in Chinese).

Su, C. L. \& Qian, X. G. (2009). The effect of different planting patterns on agronomic character and yield of Zhunliangyou 527 (a super-rice variety). Guizhou Agricultural Sciences 37, 25-26 (in Chinese).

TAO, S. S., XIANG, X. C. \& Zhang, Q. D. (2002). Studies on application methods of $\mathrm{N}$ fertilizer in scatteredtransplanting cultivation of large panicle hybrid rice. Southwest China Journal of Agricultural Science 15, 39-42 (in Chinese). 
Tian, J., Mei, S. H., Zhang, S. C., Za, X. B., Mei, J. A., Zhan, W.Z., Zhao, J.F., Fan, X. Y., Xia, Q.X. \& XIA, Z. T. (2009). Influence of seedling age and sowing amount on yield and constitution factor of late rice with no-tillage cast seedling. Hubei Agricultural Sciences 48, 796-798 (in Chinese).

Wang, G. Z., Peng, B., Lu, Z. R. \& Wang, Y. L. (2002). Study on production characteristics and high-yield control techniques of direct seeding rice. Acta Agriculturae Shanghai 18, 32-37 (in Chinese).

WANG, Q. A., Lu, C. M. \& Zhang, Q. D. (2005). Midday photoinhibition of two newly developed super-rice hybrids. Photosynthetica 43, 277-281.

Wu, J. F., PAN, X. H. \& SHI, Q. H. (2008a). Studies on the techniques of nitrogen and potassium fertilizers application of no-tillage and cast transplanting in double continuous cropping late rice. Soil and Fertilizer Sciences in China 3, 43-47 (in Chinese).

Wu, J. F., PAN, X. H., ShI, Q. H., MA, Z. W., Hu, J. H. \& LIU, Z. F. (2008b). Study on the nutritional characteristics of no-tillage and cast transplanted rice. Plant Nutrition and Fertilizer Science 14, 659-665 (in Chinese).

Wu, J. F., PAN, X. H. \& SHI, Q. H. (2009a). Effects of notillage cast transplanting on rice yield and its source-sink characteristics. Acta Agronomica Sinica 35, 162-172 (in Chinese).

Wu, J. F., PAN, X. H. \& SHI, Q. H. (2009b). Seedling standing characteristics and technology of no-tillage and cast transplanting rice. Acta Agronomica Sinica 35, 930-939 (in Chinese).

WU, J. F., PAN, X. H., WANG, L., ShI, Q. H., LiU, Z. F., Hu, J. H. \& MA, Z.W. (2009c). Studies on root characteristics of no-tillage and seedlings broadcast cultivation in rice. Hybrid Rice 24, 68-71 (in Chinese).

Wu, M. G., Zhang, G. H., Lin, J. R. \& ChenG, S. H. (2005). Screening for rice germplasms with specially-elongated mesocotyl. Rice Science 12, 226-228.

XIng, G.X., ShI, S. L., Shen, G. Y., Du, L. J. \& XIONG, Z. Q. (2002). Nitrous oxide emissions from paddy soil in three rice-based cropping systems in China. Nutrient Cycling in Agroecosystems 64, 135-143.

Xiong, H. R., Zou, Y. B., Xiong, Y. F., Li, J. J., Wen, Z. Y. \& Ao, H. J. (2005). Effects of seed pelleting agent XSW-3 on growth and yield of direct-seeded rice. Chinese Agricultural Science Bulletin 21, 242-245 (in Chinese).

Xu, G. W., TAN, G. L., WANG, Z. Q., LiU, L. J. \& Yang, J. C. (2009). Effects of wheat-residue application and sitespecific nitrogen management on growth and development in direct-seeding rice. Acta Agronomica Sinica 35, 685-694 (in Chinese).

XU, Q. H. \& ZhenG, L. D. (2006). Economics of no-tillage rice production. China Rice 5, 36-37 (in Chinese).

XU, S. H. \& JIANG, L. G. (2007). Lengthy panicle superiority and physiological mechanism in no-tillage and cast transplanting rice. Chinese Agricultural Science Bulletin 23, 118-123 (in Chinese)

Xue, Z.P., LI, J., XIN, T.E. \& Zhang, H. (2008). Preliminary study on the biology and ecology characteristics of direct sowing rice optimal seeding stages. Plateau Meteorology 27, 183-189 (in Chinese).

Yamauchi, M. \& Chuong, P. V. (1995). Rice seedling establishment as affected by cultivar, seed coating with calcium peroxide, sowing depth and water level. Field Crops Research 41, 123-134.
YAnG, W. M., LuO, Y. M., LeI, C. Y., XING, D. Y., Xu, S. H., Guo, D. D. \& Zhang, H. (2007). Research on the effect of the late-season rice cultivar and the sowing seeds quantity under direct seeding with zero-tillage. Hubei Agricultural Sciences 46, 882-884 (in Chinese).

Ying, W., PAng, X. H., Ge, C.S., Shen, J. X., Song, L. \& Kong, W. G. (2008). Suitable sowing date and sowing rate of new late Japonica hybrid rice combination Bayou 52 in no-tillage and direct seeding cultivation. Hybrid Rice $\mathbf{2 3}$, 48-50 (in Chinese).

Yu, J., Tao, G. C., Guo, X. Q., Yin, S.C. \& Xie, G. H. (2008). Tillering pattern and its effects on yield of rice directly sown after winter wheat in the Huang-Huai Plain. Scientia Agricultura Sinica 41, 678-686 (in Chinese).

YUAN, L. P. (1997). Hybrid rice breeding for super high yield. Hybrid Rice 12, 1-6.

Zadoks, J. C., Chang, T. T. \& Konzak, C. F. (1974). A decimal code for the growth stages of cereals. Weed Research 14, 415-421.

Zhang, H. C., Dai, Q. G., Qiu, F., Huo, Z. Y., Xu, K., Dong, M.H. \& YANG, H.S. (1998). Studies on the biological superiority of yield formation of broadcastingseedling rice and its high-yielding cultured way. Jiangsu Agricultural Research 19, 11-17 (in Chinese).

Zhang, H. C., Zhong, M.X., DAI, Q. G. \& ShI, Z.H. (1993). The yield formation characters of several new types scattering seedling rice and the appraisal for their using. Journal of Yangzhou University 14, 37-45 (in Chinese).

Zhang, H.X., Xu, M. L., Huang, N. S., LiU, X. J., DAI, Z. Y., ZhaO, B. H., LI, A. H. \& Guo, X. B. (2000). Techniques and approaches for the establishment of dryraised and cast-transplanted rice seedling. Jiangsu Journal of Agricultural Sciences 16, 197-203 (in Chinese).

ZHANG, Q. (2007). Strategies for developing green super rice. Proceeding of the National Academy of Sciences USA 104, 16402-16409.

Zhang, S., Guan, L., Chen, J., Hou, Q. \& Lu, S. (1996). Study on infestation, damage and eco-economic threshold of Leptochloa chinensis in direct-sowing rice fields. Acta Agriculturae Shanghai 12, 57-59 (in Chinese).

Zhang, X. M., Guo, X.S., Li, Z.F., Song, W. B. \& GuI, Y. B. (2006a). Effect of nitrogen management on matter production and yield of late rice cultivated by seedling-broadcast. Chinese Agricultural Science Bulletin 22, 189-192 (in Chinese).

Zhang, Y.P., Zhang, Y.Z., Zeng, X., Qu, H.X., Zhang, X. H., XIE, J. H. \& Tu, N. M. (2006b). Different characters of single-cropping late rice under direct-seeding and transplantation cultivation. Journal of Hunan Agricultural University (Natural Sciences) 32, 581-584 (in Chinese).

Zhao, B. H., Zhang, H.X., Xu, M. L., Huang, N.S., Wu, H.X., TANG, C. L., DAI, Z.Y. \& Zhang, Y.T. (1996). Techniques of strengthening root and erecting seeding in dry-raised and scattered-transplanting rice seedlings. Journal of Jiangsu Agricultural College 17, 17-20 (in Chinese).

Zhao, J., Luo, Q., Deng, H. \& YAN, Y. (2008). Opportunities and challenges of sustainable agricultural development in China. Philosophical Transactions of the Royal Society B: Biological Sciences 363, 893-904.

Zhao, T. J., Feng, Y.H., Han, G. G., Dong, A. I., PAN, X. S., SonG, B. \& FAN, W. G. (2009a). Effects of 
different $\mathrm{N}$ application rates on the matter accumulation and translocation of transplanted hybrid rice under notillage condition. Journal of Anhui Agricultural Sciences 37, 1641-1643 (in Chinese).

Zhao, T. J., Feng, Y.H., Han, G. G., Fan, W. G., Wu, Z. H., Dong, A. I., Song, B. \& PAN, X. S. (2009b). Effects of fertilizer- $\mathrm{N}$ application rates and tillage patterns on the population quality and yield of super hybrid rice Qiannanyou 2058. Hybrid Rice 24, 57-61 (in Chinese).

Zhou, C. H., Gao, J. H., Zhang, X. H., Wang, S., Lei, C. Y., YANG, W. M. \& XING, D. Y. (2008). Study on the optimum sowing day with no-tillage and direct seeding of late-season rice on Jianghan Plain. Journal of Anhui Agricultural Sciences 36, 6236-6237 (in Chinese).

ZHou, X.Z. \& TANG, C. Y. (2008). Effects of different plowing methods on economic characters of rice. Hubei Agricultural Sciences 47, 764-766 (in Chinese).

ZHU, D. F. (2000). Bridging the rice yield gap in China. In Bridging the Rice Yield Gap in the Asia-Pacific Region (Eds M. K. Papademetriou, F. J. Dent \& E. M. Herath), pp. 69-83. Bangkok, Thailand: FAO.

Zou, Y. B., Zhou, S. Y. \& TANG, Q. Y. (2003). Status and prospect of high yielding cultivation researches on China super hybrid rice. Journal of Hunan Agricultural University (Natural Science) 29, 78-84. 